\title{
Las metarrepresentaciones en español hablado
}

Leonor Ruiz Gurillo

\section{(Grupo GRIALE).}

Universidad de Alicante 


\section{Esquema}

-1. Introducción: qué es una metarrepresentación

-2. Las metarrepresentaciones en la lengua

- 3. Algunos tipos de metarrepresentaciones:

discurso directo e ironía 


\section{Introducción}

- Metarrepresentación:

Es una representación de otra representación (Wilson, 2000)

- Corpus empleado: Briz y grupo Val.Es.Co. (2002): Corpus de conversaciones coloquiales. Madrid, Arco Libros. 
2. Las metarrepresentaciones en la lengua: 4 tipos

-1. Las representaciones mentales de las representaciones mentales: PENSAMIENTO "Juan piensa que va a llover".

-2. Las representaciones mentales de las representaciones públicas: PENSAMIENTO: "Juan dice que va llover". 
2. Las metarrepresentaciones en la lengua: 4 tipos

- 3. Las representaciones públicas de las representaciones mentales:

ENUNCIADO "Juan cree que va a llover".

- 4. Las representaciones públicas de las representaciones públicas: ENUNCIADO "Juan dice que va llover". (Sperber, 2000:3). 
2. Las metarrepresentaciones en la lengua: 4 tipos

• 3 y 4 interesan a los lingüistas

\section{- APLICACIÓN:}

- Uso interpretativo del lenguaje: tropos y actos de habla 


\section{Las metarrepresentaciones en}

la lengua: 4 tipos

"La metáfora implica una relación interpretativa entre la forma proposicional de un enunciado y el pensamiento que representa; la ironía implica una relación interpretativa entre el pensamiento del hablante y pensamiento o enunciados atribuidos a otros; (...) las interrogativas y las exclamativas implican una relación interpretativa entre el pensamiento del hablante y otros pensamientos deseables".

(Sperber y Wilson, 1994:283). 
3. Algunos tipos de metarrepresentaciones

- (1)

- A: Estoy viendo las obras el AVE

- B: ¿Las obras del AVE?

- A: Sí

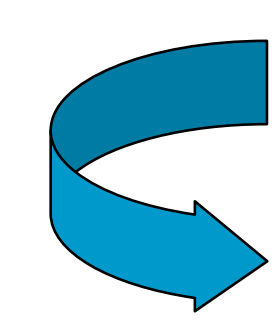

-Grado de metarrepresentación

-Orden de habilidad metarrepresentacional 


\section{Grado y orden}

- (1)B pregunta

si $A$ dice que

A ve las obras del ferrocarril de alta velocidad (Metarrepresentación 2ํgrado)

- -GRADO

DE METARREPRESENTACIÓN (explicaturas e implicaturas) 


\section{Grado y orden}

[Enunciado] HABLANTE B

[Enunciado] HABLANTE A

[pensamiento]

(Habilidad metarrepresentacional de $2^{\circ}$ orden)

- ORDEN

DE HABILIDAD METARREPRESENTACIONAL ( $1^{\circ}$ orden, $2^{\circ}$ orden, orden superior) 
3. Metarrepresentaciones:

el discurso directo

2 ÓRDENES:

1.Metarrepresentaciones de $1^{\circ}$ orden: representan pensamientos $u$ opiniones nunca formulados

(alguien dice lo que piensa)

2.Metarrepresentaciones de 2 o orden: representa un discurso previo

(alguien dice lo que alguien dice) 


\section{Metarrepresentaciones:}

el discurso directo

(4)c: me dice mire $\downarrow$ un muñeco que sale en la tele $\downarrow$ no se me olvidará en la- en la VIDA/ que es rosa y tiene muchos pinchos $\rightarrow$ ¿usted sabría decirnos el nombre? digo pues Espinete $\downarrow$ [....] [yo digo=]

A:

[normal]

c: = jost-Á! pues sí que he ganao yo cinco mil pesetas fácil

(Briz y grupo Val.Es.Co. (2002:235) [H.25.A.1:109-115] 


\title{
Grado de metarrepresentación
}

Discurso directo prototípico

$C$ pretende que

\author{
A crea que \\ que $A$ dice que \\ el bromista dice
}

mire $\downarrow$ un muñeco que sale en la tele (...)/ que es rosa $y$ tiene muchos pinchos

Metarrepresentación de $4^{\circ}$ grado 


\section{Grado de metarrepresentación}

\section{Discurso directo no prototípico}

C pretende que

A crea que

C piensa

¡OST-Á! / pues sí que he ganao yo cinco mil pesetas

fácil.

Metarrepresentación de 3ํgrado 


\section{Metarrepresentaciones de $2^{\circ}$ orden}

\section{Discurso directo prototípico}

me dice mire $\downarrow$ un muñeco que sale en la tele (...)/ que es rosa y tiene muchos pinchos

[Enunciado]HABL.2

[Enunciado]HABL.1

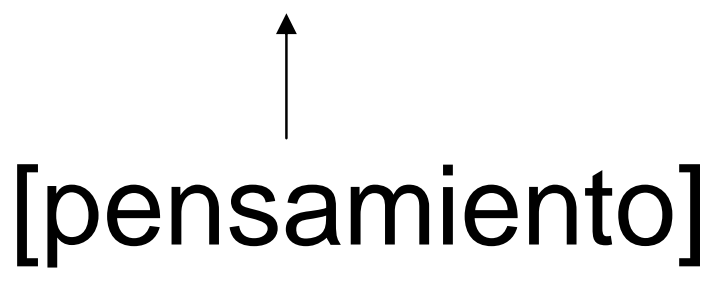




\title{
Metarrepresentaciones de $1^{\circ}$ orden
}

\section{Discurso directo no prototípico}

yo digo ¡OST-Á! /pues sí que he ganao yo cinco mil pesetas fácil

\author{
[Enunciado] HABL. 1 \\ [pensamiento]
}




\section{$1^{\circ}$ orden y $2^{\circ}$ orden en el discurso directo}

\section{ORDEN}

me dice mire $\downarrow$ un muñeco que sale

FUNCIÓN en la tele (...)/ que es rosa $y$ tiene muchos pinchos 1ORDEN

yo digo ¡OST-Á! / pues sí que he ganao yo cinco mil pesetas fácil

NARRATIVA

FUNCIÓN

ILUSTRADORA

(APRECIATIVA

O DE AUTORIDAD) 


\section{Metarrepresentaciones:}

la ironía

\section{USO INTERPRETATIVO \\ $+$ \\ USO ECOICO}

Un enunciado es irónico porque es ecoico (Wilson y Sperber, 2004:264) 


\section{Metarrepresentaciones: la}

ironía

(6)

A: ¿A QUÉ HORA?

$\mathrm{C}$ : pínchate ahora

A: ¡cha!

B: papa

A: pínchate ahora $\downarrow$ (1) te estoy diciendo/ QUE HEMOS PEGAO DOH O TREH TRAGOH DE GÜIHQUI $\downarrow$ pos voy y me pincho ahora $\uparrow$

(1) Con tono de desacuerdo

(Briz y grupo Val.Es.Co., 2002:292-293. [RV.114.A.1:29-34] 


\section{Inferencias como discurso directo}

A: pínchate ahora

A pretende que

$C$ entienda que

A dice que

$\mathrm{C}$ dice

pínchate ahora

Metarrepresentación de $4^{\circ}$ grado

USO INTERPRETATIVO 


\section{Inferencias como ironía}

A pretende que

$C$ entienda que

A se burla de que

A dice que

C dice

pínchate ahora

Metarrepresentación de 5ํado

USO INTERPRETATIVO+ USO ECOICO 


\title{
3. Tipos de
} metarrepresentaciones: la ironía

\author{
[Uso interpretativo [[Uso ecoico] [Uso irónico]]]
}


3. Tipos de

metarrepresentaciones: la ironía

-Las metarrepresentaciones de la ironía son de $4^{\circ}$ grado o superiores.

-La comprensión de que el hablante se está burlando de algo es básica y fundamental. ( $\rightarrow$ USO ECOICO) 
3. Tipos de metarrepresentaciones: la ironía

-Supone una habilidad metarrepresentacional de un orden superior a la metáfora o la hipérbole. -Emplea habilidades metarrepresentacionales de órdenes inferiores. Así, la metáfora, la hipérbole, los evidenciales o el discurso directo pueden convertirse en indicadores de la ironía. 


\section{Habilidades metarrepresentacionales}

Habilidad de orden superior (IRONÍA)

\section{Indicadores irónicos}

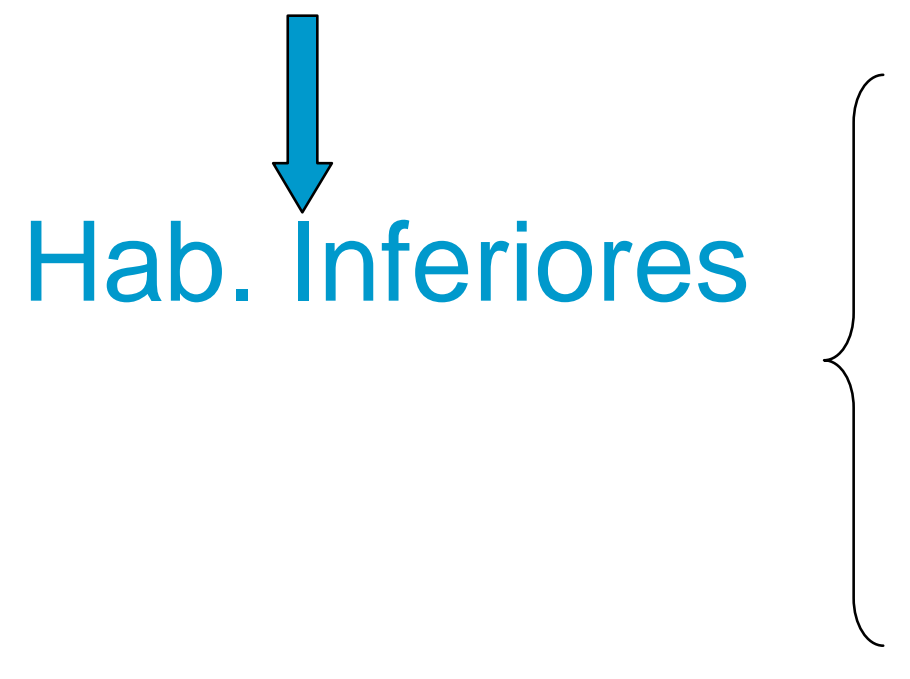

metáforas

hipérboles

evidenciales

discurso directo

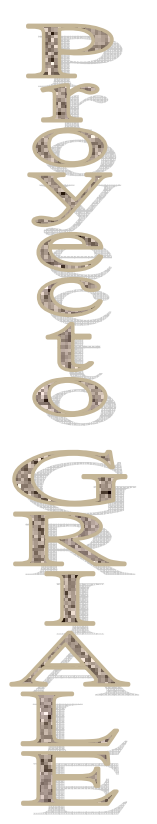

http//:griale.ua.es 